\title{
Cultural Differences in Trademark Translation
}

\author{
WANG Jian-ying \\ Qingdao University of Science and Technology, Qingdao, China
}

\begin{abstract}
With the globalization of commerce, especially with China's entry into the World Trade Organization, the competition of products among countries has become more and more fierce. Almost all companies and corporations are making every effort to make known their products and services. Before entering the world market, an important thing that should be done is to let foreign customers become familiar with and have a favourable impression of the relevant products and services. Customers choose products according to the quality of the products or the impression they have of the products, the latter of which usually comes from the influence of good trademark translation. Launching products successfully into the target market is to a large extent decided by distinctive sign of some kind which is used by a business to uniquely identify its products and services to consumer Because of different cultures, social environments, and economic conditions, etc., customers in different part of the world have different consumption values, so it is of great importance to take culture into consideration when translating a trademark. Because of the fact that trademarks are mainly described by languages, there are some difficulties in trademark translation. Then, in this paper, except some common knowledge about trademark, the differences between English and Chinese trademarks are shown and some mistranslations are given. In order to avoid the cultural interference in translation, some common skills and some creative skills are discussed. And at the end of this paper, some general principles of trademark translation are provided for good trademark translation.
\end{abstract}

Keywords: trademark, cultural differences, translation, skills

\section{Introduction}

A trademark is a symbol of a product or service an outcome of the development of the commodity economy. It is intended to identify the products or services of one seller or one group of sellers and to differentiate them from their competitors. A trademark is a significant feature of the product or service.

The translating of a trademark is a reverse transformation process by decoding the encoded. Trademark translation is "blending in the translator's feeling and thought, knowledge level, mental state, cultural awareness, living environment and various kinds of related context subjective factors and objective factors”, and trademark translation accords with translated concept of Semiotics. "Translation is a kind of language-communicational activity in a cross-cultural sense; a symbol's significance should be studied in a certain context of the whole communication process". American linguist Rosalie mentioned in her essay "Bias-Free Language: Some Guidelines” (1991) said that “culture shapes language and then language shapes culture” (p. 1). She thought language both reflects and shapes societies. That is to say trademark translation is the transplantation of two kinds

WANG Jian-ying, associate professor of School of Foreign Language Studies, Qingdao University of Science and Technology. 
of cultures. In this paper, apart from some general information about brands, the cultural differences between English and Chinese brands are shown and some mistranslations are given. At the end of the paper, some general principles for good brand translation are provided.

\section{Overview of Trademark}

\section{Definition of Trademark}

Trademarks are the marks of goods and commercial services. They are a mark that commodity producers, operators, and service providers create to make their products or services different from other similar goods or services. These marks are shown by texts, graphics, or a combination of text and graphic. They often placed on goods or the packaging of goods, or on the premises of a service establishment.

\section{Function of Trademark}

Trademark has an important effect on trade, acting as a bridge between producers and customers. A good trademark can provide important information about the product, attract consumers, and achieve the aim of promoting products. The most significant usage is to persuade people to buy their products. In order to achieve these purposes, a good trademark usually has informative, aesthetic, expressive, and imperative functions.

Informative function. Informative function is the most important of the four functions of a trademark. This means that a good trademark must be informative. A good trademark usually provides the consumers with some information about the products, such as the functions, values, and characteristics of the product.

First of all, most trademarks let customers know the basic functions of the product. For example, “感冒通”, and “金嗓子” are common trademark of medicine. “感冒通” means to recovery of the common cold in Chinese, successfully showing the effect of this medicine for common cold. “金嗓子” means a sweet and clear voice in Chinese, successfully indicating the function of this medicine for one’s throat. “舒肤佳” (safeguard) is a trademark for a fancy soap in Chinese, which means people who use this soap will feel it is comfortable on the skin. Some other examples are “思肤亲” (cosmetic), “美体小铺” (cosmetic), “美加净” (cosmetic), and “健力 宝” (beverage), from which customers can get some information about the functions of these products.

Secondly, a trademark can reflect some certain characteristics of a product. For example, “华伦天奴” (clothing) suggests that this kind of cloth makes people look beautiful, dignified, and graceful.

Thirdly, many trademarks provide information about the values of certain products. For example, “珍珠” (jazz drum) hints that the drum of this brand is as precious as a pearl.

Finally, trademarks often tell target customers whom the goods are suitable for. For example, “孩之宝” (toy), “酷宝宝” (children’s cloth), and “好宝宝” (children’s book) inform people these goods are for children.

Distinguishable function. As commodities, different products or services have different quantities, qualities, and services. Trademarks are like the faces of the products. It is not difficult to see that different trademarks have the same function, which is to distinguish one kind of products or services from another kind. Trademarks are like a person's name, but they can do much better than communicate a name, because trademarks are the unique signs of products or services and none of them are repeated. That is to say, when customers read a trademark in a supermarket or in a public place, they can easily, quickly, and clearly tell what kind of product or service the trademark is related to. A trademark assists consumers to know the features of a certain product or 
service and the differences between a certain product and other similar products. In a word, customers would seldom make a mistake when they are choosing products or services by reading the trademarks.

Aesthetic function. Aesthetic function refers to trademarks' ability to create a sense of beauty, and offer the audiences an aesthetic experience. The beauty in form mainly includes phonetic beauty and graphic beauty; the beauty in context generally means semantic beauty and image beauty. The aesthetic function can help people remember the goods easily and achieve the goal of advertising. So a good trademark should be short.

Expressive function. The expressive function means that a trademark should transmit some information about the products or services such as function, characteristic, value and so on. For instance, "Benz” (car) had been translated into Chinese as “本茨”, “鹏驰”, “平治”, but the most successful translation was “奔驰”, which not only sounds like the source trademark "Benz” but also advises people this trademark is about a car.

Imperative function. Imperative function is also called the vocative function. It means that a good trademark should inform people of the value of certain goods, attract consumers, and persuade them to buy. As a consequence, it achieves the aim of promoting goods. A good trademark often tells people the value of the goods, and can persuade people to purchase it. For example, “联想” (computer), which means people can make the connection in their mind. This trademark is very convincing, because it tells people about the value of this kind of computer.

\section{Culture and Trademarks}

Culture is the effects obtained by individuals or groups from generation to generation, including the knowledge, experience, beliefs, values, behaviors, attitude, meaning, hierarchy, religion, the concept of time, point of view, spatial relation, cosmology, and so on. Every culture in the world both has universality and individuality, every culture has its own characteristics, and every culture coexists equally and cannot replace each other. Language is not only a tool of thinking and communication, but also a reflection of social culture, and it affects people's thoughts. Because the individuality of each culture is greater than the universality, this kind of difference reflects the high level that of various considerations that trademark translation is bound to give rise to.

\section{Cultural Differences in Language}

The East and the West have different geographic locations, history, philosophy, and cultural traditions, and because the linguistic form itself is different, there are not many conditions of equivalence in Chinese and English words. During translation, therefore, the translator should not only understood the literal meaning of the words themselves, but also understand the cultural significance of the words. If we ignore the differences between two cultures, using the native language mode of thinking to comprehend the concept of target language culture, we will cause a phenomenon called "cultural aphasia”. This kind of translation will not achieve the required effects, and is very likely to give a bad impression in foreign consumers' minds, or even destroy the brand. The difficulties in translation caused by cultural differences reflect directly a lack of vocabulary and semantic conflicts. Namely, the cultural information carried by the source language cannot be found in the target language vocabulary, or it is contrary to cultural information in the target language. In general, the following aspects are cultural differences in trademark translation.

English vocabulary vacancies. The cultural information carried by the trademark of the source language, Chinese, cannot be found in English vocabulary. That is to say, there are no peer-to-peer words. This 
phenomenon is called completely vacancy. Donnson Chen listed more than 200 such words in translating from Chinese to English, for example, “功夫” (Kung fu); “太极” (Tai chi); “狗不理包子” (Goubuli baozi), etc.. These Chinese concepts do not have equivalence in Western culture and there is no corresponding vocabulary.

Different aesthetic sense and consumer psychology. Different ethnic groups have different aesthetic orientations. For the same thing, one group may consider it very beautiful while another may think it is ugly. In some home-made cosmetics’ instructions, “增白” is translated into “whiten the skin”. Chinese people think white skin is very beautiful, while Western people want their skin to be brown, which represents health. They consider white skin as representing poverty and illness instead of beauty. Who would buy cosmetics based on this aesthetic sense?

\section{English-Chinese Semantic Conflict}

Semantic conflict occurs when words from the Chinese source vocabulary and the vocabulary of English, the meaning of the same initiative concept (that is the original meaning), but they have diametrically opposed cultural semantics. The cultural semantics of terms are related to national history, religion, customs, knowledge, and psychological factors, which have national colors. For example, we might take the "Butterfly" brand electronic stove. Chinese people see "butterfly" as a symbol of friendship and love. When we see a butterfly we might think of the poignant and moving love story of LIANG Shan-bo and ZHU Ying-tai. But in Western countries, people think butterflies are something very frivolous. In English, a social butterfly is a social beauty (“交际花”). If a company uses “butterfly” as their trademark, English speakers will doubt whether the product is good and durable.

\section{The Problems of Trademark Translation in China}

Some trademarks are translated literally and directly into English, translators are not well aware of the differences in cultures and nations, so the translation is contrary to the English culture. The followings are some major examples of cultural conflicts in trademark translations.

\section{Problems in Literal Meaning}

Quite often, we find that Chinese words with positive sentiments have just the opposite meaning in English, or they are beyond the understanding of English people, and vice versa. For example, a brand of exported lipstick which is made in China, is named “芳芳” (Fangfang). In China, “Fangfang” is a nice name which gives people a good impression. The word “芳” is usually used to describe flowers which are beautiful and charming, and girls named “芳” are pretty and elegant. In Chinese, there are many other phrases containing the word “芳”, such as “芳容” (beautiful-looking), “芳龄” (young girl’s age), “芳芳” (good-smell), and so on. When it is translated into English in Chinese Pinyin, it is "Fangfang”. However, instead of the impression of pretty and beauty, a feeling of terror comes into the English readers' minds. There is a coincidence that the Pinyin "fang” is the same as the English word "fang”. In English, a "fang” is a long and pointed tooth. In mammals, a fang is a canine tooth, used for biting and tearing flesh. In snakes, it is a venom-injecting tooth. It is easy to imagine that when English ladies read this word, a dog or wolf with long and sharp tooth, or a snake with its poisonous tooth may come into their mind., so who will buy this kind of lipstick?

Another example, “蓝天” (Langtian) is a toothpaste brand made in China. It is a very popular brand in China and in southern Asia but it fails in the American market. The translation is the key. The trademark “蓝天” 
translated into "Blue sky" and "Blue heaven" in America. In Chinese, wide blue sky and white clouds are the symbols of freedom, happiness, and elegant, people like this implied meaning, and they want to buy the goods. But in English countries, blue sky is a word which means useless, with less value, not steady, and an invalid negotiable security. Supposing you are the customer, will you buy these "useless" goods? In addition, "Blue heaven" is the name of one kind of drug, with a blue capsule, and has existed in Western countries for a long time before “蓝天” came into those countries. So when the foreign customers read this trademark, they will think this is a kind of drugs and do not dare to buy.

\section{Problems in Connotation}

Different region and culture between East and West make people have different thinking patterns. For example, a kind of shampoo for the bath named “蜂花” (Fenghua) in China. Maybe the producers want to tell customers this shampoo is perfumed and consists of many spices, which is like the bees helping to collect them from hundreds of flowers. But this trademark is beyond the comprehension of the English people. English people do not like this name, because they think that on the body of a bee there are many invisible hairs and that may make people feel uncomfortable. So few people would like to buy this shampoo.

“蝙蝠” (Pinyin “Bianfu”) is a symbol of lucky and happiness. It has a good impression in Chinese people’s minds, because “蝠” (fu) and “福” (happiness) are homonyms in Chinese. “蝙蝠” is a good trademark for products such as jewelry and glasses. But things are different in English. What do English speaking people think of "bat"? They think that the "bat" is a blind, ugly, and unlucky animal which only flies at night, and never dares to open its wings in the daylight. In the West, bat stands for "death", and if a bat flies into your house by accident, that may be an ill omen for you. Also, English people always compare a bat to a blind old witch or a vampire. So if you are an English speaking person, would you want to wear a "Bat” necklace or glasses?

Here is another example. The Chinese people treat the magpie as a lucky bird which can bring good news to people. As the saying goes: "If there is a magpie standing in the tip and singing , good news will come”. In China, every 7th July in the lunar calendar is the day the herd-boy and the weaving-girl are supposed to meet and the magpies will gather together as a bridge to help them. In Chinese, “喜鹊” (“Magpie”) is a good name for radio and sound equipment. However, in Western countries people do not think so. They think the magpie is a bird that whistles day and night, making noise, building nests here and there, and bringing rubbish into their nests. A magpie is also compared to a person who treasures useless things with no intention of throwing them away, and a person who chatters without stopping. In Sweden, people associate magpies with witchcraft and the Scotch think that if a magpie come into the house it means someone will die. Who would be willing to bring a noise maker or sinister creature into the house instead of avoiding them?

\section{Problems in Usage}

Some terms which originated in Chinese are frequently spoken and written by English people, but they are never used with their literal meaning. Therefore, we should be careful of them in trademark translation, otherwise we could make a joke. For example, a brand of exported battery is named “白象” (“Baixiang”). It is translated directly into English as "White Elephant”. It may be a completely correct translation but in English, a "white elephant" is an idiom meaning a burdensome and useless possession. The result is that this kind of battery does not sell well. Who would be foolish enough to spend money on a burdensome possession or useless rubbish? 
Here is one more example to explain this point. “白领” (Bailing), a brand of pen made in Shanghai, China, is directly translated into English as "White Feather". As a result, it failed to break into overseas markets. What is the reason? In English, there is an idiom "to show the white feather" which means deserting on the eve of a battle. That is to say, a white feather has the connotation of a coward. Supposing that when someone sees a pen in your hand or in your suit pocket, what would they think of you? How would you feel when you realize that they think you are a coward?

Here are some political metaphor examples. “大鹏” (“Dapeng”) canvas shoes are translated into “ROC”. Dapeng is a super bird in Chinese fairy tales, and it also a great bird in Western mythology. In this sense, there is no problem with the translation. But as a trademark, the letters are capital letters, and it becomes the same as the abbreviation of “中华民国”. It is of course not desirable. The trademark “白熊” (“Baixiong”) is translated as "Polar Bear". The polar bears live in the Arctic, so they are called "polar bears" in English. However, the two terms have special meanings in international policy so in order to avoid misunderstanding the translation can be changed to "White Bear".

\section{Trademark Translation Skills and Principles}

We all know there are differences between Chinese and English, and we should pay attention to them and be aware of the cultural conflicts between the two languages. We should develop a cross-cultural consciousness and try to reduce or avoid making mistakes in cross-cultural communication. The following discusses some skills of translating brands from a cross-cultural communication perspective.

\section{Common Skills}

When it relates to trademark translation, the common skills are transliteration, semantic translation, and trans-semantic translation.

Transliteration. Transliteration is the way by which the trademark is translated according to the pronunciation of the source language. The translators pick up words in the target language with the same pronunciation in the source language. The goal of this approach is to comply with the linguistic rules and deliver the source language culture. Many trademarks are translated in this way. The first and the most successful example of trademark translation is an American drink "Coca-Cola". The trademark of this black drink is composed by two words: “coca” and “cola”. At first, “coca” is translated into “古柯” which is a plant growing in South America , and “cola” was translated into “古拉” which is another kind of plant growing in Africa. But the sales volume was not good. Now it is translated into “可口可乐”, which makes consumers feel sweet and happy. The drink has become the most popular drink in the world. Similar examples are “Pepsi-Cola” (百事可乐) and “Lactov” (乐口福). Other examples are: the famous Finland electronic product trademark “Nokia” (诺基亚), the largest fast food trademark “McDonald’s” (麦当劳), the suit trademark “Pierre Cardin” (皮尔卡丹), and so on.

Semantic translation. Semantic translation is the way by which the trademark is translated according to the meaning of the source language. The goal of this approach is to transfer the main meaning of the source language and make the consumer of the target language understand it easily. Many trademarks are translated in this way. For example, the popular car “Crown” is translated into “皇冠” in Chinese, and the Chinese bicycle “永久” into the English brand "Forever”, and so on. 
Trans-Semantic translation. Trans-semantic translation, combining with transliteration and semantic translation, is a high skill which needs a solid foundation and rich imagination. Taking both the pronunciation and the meaning of the source language into consideration, trans-semantic translation is a translation skill reflecting the features of the products. This is the best way to translate the trademark of common products. For example, a shoes brand "Warrior” is translated into “回力” in Chinese. It has a similar pronunciation in English word "warrior", and in Chinese it means having a larger power to do anything. Another example is the cosmetic brand “Clean Clear” which is translated into “可伶可俐”. The pronunciation “可伶可俐” sounds very like “Clean Clear”, and it means a skin white and tender, and the girls who use it are cute and beautiful.

\section{General Principles in Trademark Translation}

With the development of the economy and the continuing of the open policy, trade between China and foreign countries is becoming increasingly frequent. More and more people are beginning to realize the importance of trademarks. Trademark translation is a complex skill with important economic effects and brings more attention to the business. All trademark translation may adhere to the following principles.

Faith in the products. The trademark is a mirror of a certain product or service. Either the native language trademark or the translated trademark has something to do with the product. Different products have different trademarks.

Simple and creative. Trademark translation almost always has no more than four words. The trademark should be simple and easy to read and remember. If the trademark translation is creative it can show its special features, then it may give consumers a strong impression. That may make products have a high rate of sale in the market.

Colorful and imaginative. A good trademark translation gives reader the information of a certain product or service. It also can make consumers imagine something when they first read the name of product, and can give some detailed information about the goods. By doing that, the brand may become more popular.

Complying with the culture of the source language. Trademark translation is for the target language readers. If they cannot understand it, the translation is useless. If they misunderstand it, that means the translation has failed and can even create a bad effect on the product. So trademark translation should comply with the culture of the source language.

\section{Conclusions}

To some extent, a trademark is more important than the product itself. Terms in different cultures have different cultural connotations and can arouse different associations. The producers rack their brains to create trademarks which are humorous, vivid and vigorous, and unique and novel, to give a deep impression to customers and win over opponents in competitions. By reading this, the trademark translation is a very important skill. When trademarks are being translated, cultural differences should be considered and the characteristics of the products should also be paid attention to. There are many skills involved in trademark translation. The common skills are transliteration, semantic translation, trans-semantic translation, and effectiveness translation. The creative ways of character translation, approximation translation, elegant translation, and translating flexibly are the skills to make trademark translation better. In brief, all the skills are basic to the rules of faithfulness to the product, simple, creative, and easy to remember, colorful and imaginable and complying with the native culture. 


\section{References}

LIU, X. P. (2006). Cultural differences and trademarks translation. Journal of Anhui Agricultural University (Social Sciences), 2.

MA, X. Y. (2004). Cultural disparities and the translations of "brands" between English and Chinese. Journal of Anyang Teachers College, 1 .

Nida, E. (2004). Language, culture, and translating. Shanghai: Shanghai Foreign language Education Press.

Rosalie, M. (1991). Bias-free language: Some guidelines. In G. Goshgarian (Ed.), Exploring language (pp. 313-324). New York: Longman.

Sager, J. C. (1997). Text type and translation. In A. Trosboryed (Ed.), Text typology and translation (p. 25). Amsterdam and Philadelphia: John Behjamins Publishing Company.

Samouvor, L. A., \& Porter, R. E. (2000). Communication between cultures. Beijing: Foreign Language Teaching and Research Press.

Tylor, E. B. (1871). Primitive culture (pp. 52-56). London: John Murray.

Verschueren, J. (1999). Understanding pragmatics. London and New York: Arnold.

XIA, W. Q. (2007). On the translation of trademarks from the perspective of adaptation theory. Journal of Anhui University of Technology (Social Sciences), 3.

ZHAI, B. X. (2004). The transliteration in the translating of brand names and its reasons. Journal of Anhui Agricultural University, 2. 